\title{
Solar Cycle Dependence and Seasonal Variation of Ionospheric Radio Scintillations
}

\author{
Eduardo Perez Macho, Emília Correia, and José Henrique Fernandez
}

Abstract - The importance of studying ionospheric phenomena increases as society modernizes and makes use of technologies that require the usage of orbiting satellites. Their signals suffer scintillation at the ionosphere due to its irregularities. This work aims to quantify the moderate to strong scintillations at three different regions (magnetic equator and its southern and northern regions) during a full year of solar minimum and maximum. Its occurrence increases substantially with solar activity and is higher at the regions of Equatorial Ionospheric Anomaly crests. There is also an important increase of scintillation during the months of spring and summer of the southern hemisphere.

\section{Introduction}

Modern society increasingly depends on technology such as the Global Navigation Satellite System (GNSS), with satellites orbiting the Earth at around $20,000 \mathrm{~km}$ altitude that communicate with ground receptors through radio signals. These signals, when crossing the ionosphere, from 70 to over $1000 \mathrm{~km}$ of altitude, can be subject to amplitude or phase scintillations, caused by ionospheric irregularities [1]. These irregularities can be in the form of plasma-depleted structures, known as plasma bubbles, which develop at the magnetic equator after sunset and rise up to altitudes higher than $1200 \mathrm{~km}$. After that, the plasma bubbles propagate to the regions of the crests of Equatorial Ionospheric Anomaly (EIA), at around $15^{\circ}-20^{\circ}$ from the magnetic equator, north and south, where the most intense scintillations are expected to occur [2].

In this study, we collect data from Global Positioning System (GPS) receivers in three regions of South America to investigate the amplitude scintillation's difference between solar minimum and maximum, between the EIA crests and the magnetic equator, and between seasons of higher and lower occurrence. Although these differences have been previously studied [e.g., 2-6], these investigations have been done

Manuscript received 7 December 2021.

E. P. Macho is with Institution Universidade Mackenzie, Rua da Consolação 930, 11302-907, São Paulo, Brazil; e-mail: eduardopmacho@gmail.com.

E. Correia is with Institution Universidade Mackenzie, Rua da Consolação 930, 11302-907, São Paulo, Brazil, and Institution Instituto Nacional de Pesquisas Espaciais (INPE), Av dos Astronautas, 1758, 12227-010, São José dos Campos, Brazil; email: ecorreia@craam.mackenzie.br.

J. H. Fernandez is with Institution Universidade Federal do Rio Grande do Norte, Escola de Ciências e Tecnologia, Anel Viário Contorno do Campus s/n-Capim Macio, Natal-RN, 59078-970, Brazil; e-mail: jose.henrique.fernandez@ufrn.br. qualitatively, and the novelty of this study is their quantification, covering a full year of solar minimum and solar maximum at the magnetic equator and northern and southern crests of EIA.

\section{Data and Method}

The data used in our investigation are provided by the Low-Latitude Ionospheric Sensor Network (available at http://lisn.igp.gob.pe). The investigation is done using the amplitude scintillation of the GPS signals received at Boa Vista (BOA; dip angle 18.6N) and Cuiaba (CUI; dip angle 17.5S), representative, respectively, of the northern and southern EIA crests and Huancayo (HUA; dip angle 00.3S) at the magnetic equator. The dip angle considered here is for January 2015. Figure 1 shows the location of the GPS stations used in this study and the magnetic equator line. The GPS data used to characterize the scintillations during solar minimum are of the year 2019 for BOA and 2009 for HUA and CUI and during solar maximum are of the year 2012 for BOA and CUI and 2014 for HUA. The reason we chose the selected stations and years is to have the largest availability of data as possible. Figure 2

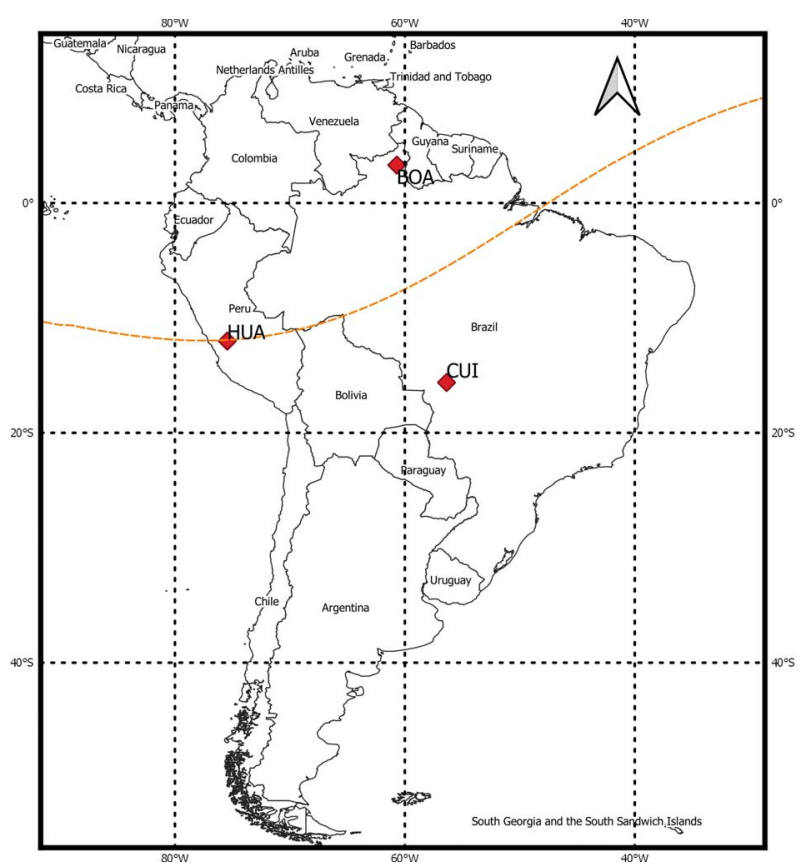

Figure 1. South America map showing the location of the GPS stations used. The dashed orange line refers to the magnetic equator, provided by the International Geomagnetic Reference Field (IGRF-12) model for 2015. 


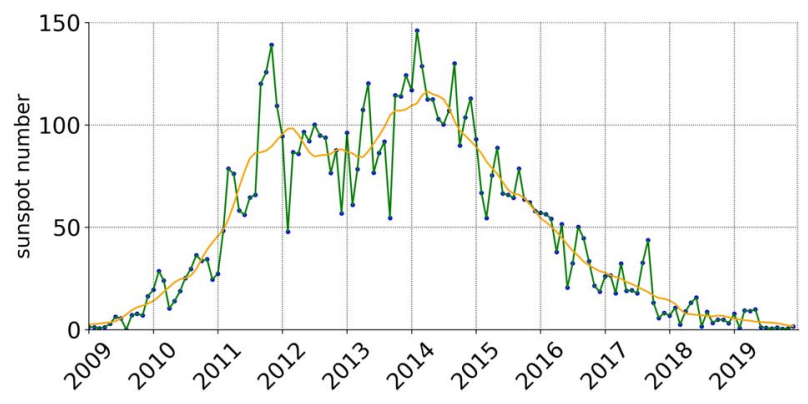

Figure 2. Sunspot number from 2009 and 2019 (orange line refers to the smoothed monthly values). Data provided from Space Weather Prediction Center/National Oceanic and Atmospheric Administration. shows the sunspot number from 2009 to 2019 (solar cycle 24), which presents the similarities of solar activity between 2009 and 2019 (solar minimum) and 2012 and 2014 (solar maximum).

The investigation is done using the S4 index, which is related to the amplitude scintillation averaged over $60 \mathrm{~s}$, given by the GNSS receivers every $60 \mathrm{~s}$ period. We used only the satellites with elevation angles above $30^{\circ}$ to minimize errors due to multipath [7], and the S4 index was verticalized using the equations given by [8] in order to account for geometrical effects on the measurements due to different elevation angles.
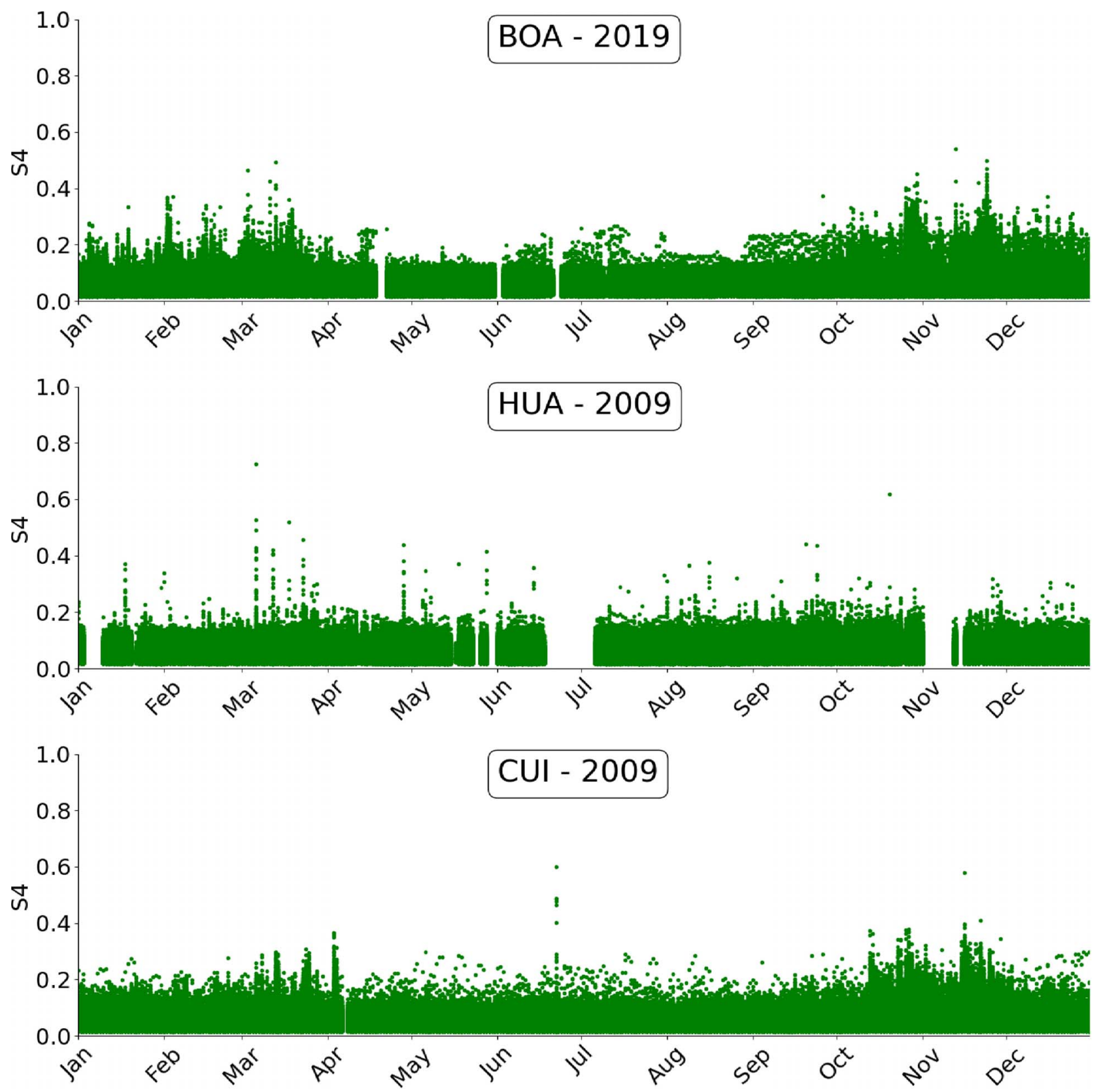

Figure 3. S4 index measured during solar minimum years at BOA (northern EIA crest), HUA (magnetic equator), and CUI (southern EIA crest). 

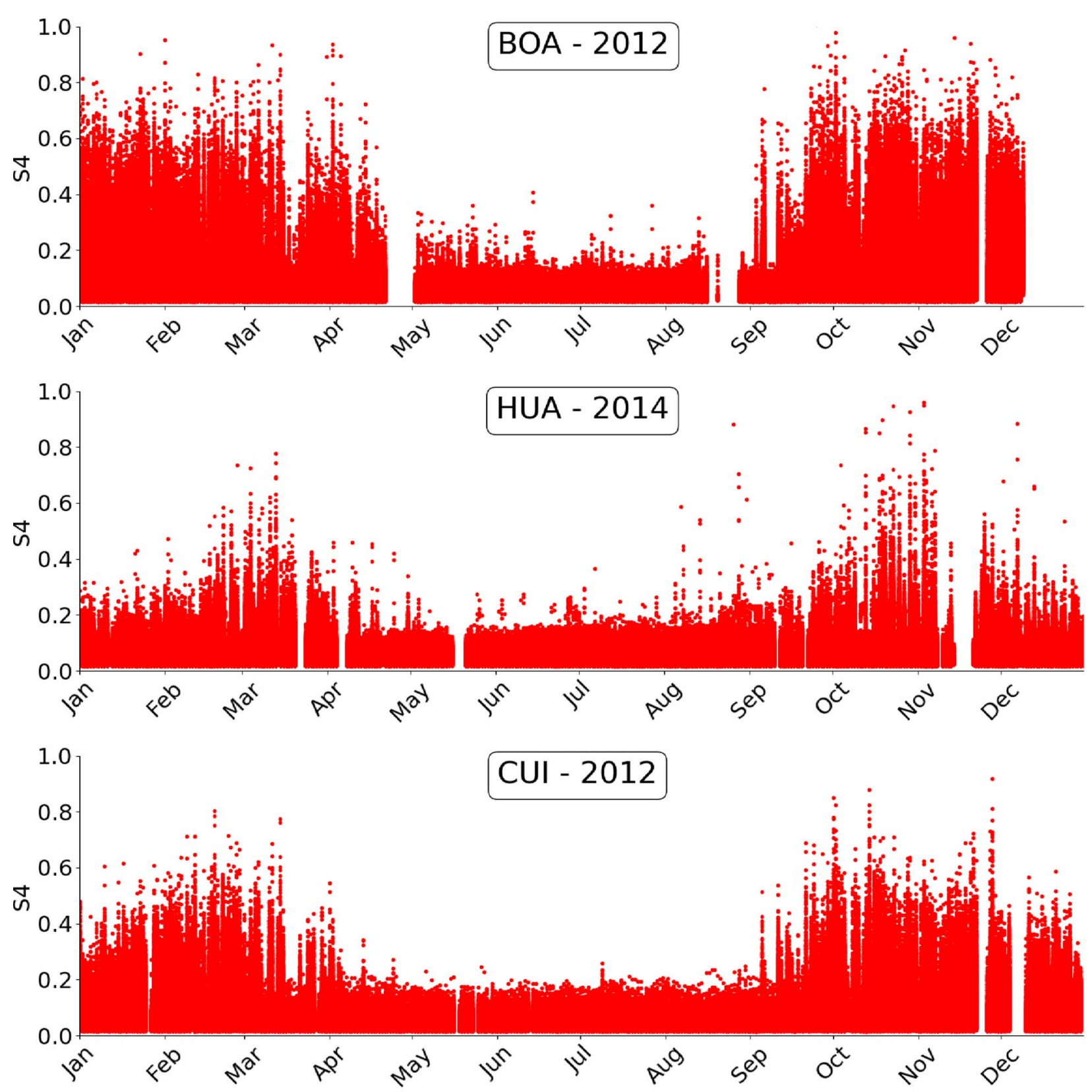

Figure 4. S4 index measured during solar maximum years at BOA (northern EIA crest), HUA (magnetic equator), and CUI (southern EIA crest).

\section{Results}

Figure 3 shows the $\mathrm{S} 4$ behavior during the years of minimum solar activity. The S4 index shows a predominance of values $\leq 0.2$ all over the year in the three regions, EIA crests, and magnetic equator. But during the equinox months (February-March and October-November), the S4 increases, reaching $\sim 0.4$ values in the EIA crests. Every minute, each station furnishes S4 measurement information from around eight to 12 satellites, which gives at least 4 million values of measurement. The number of satellites with elevation angle over $30^{\circ}$ is $50 \%$ on average, around at least 2 million. From this amount, the total number of measurements in which S4 was over 0.2 was 2195 at BOA, 135 at HUA, and 965 at CUI, which means that the occurrence of scintillations from moderate to strong was higher at the crests of EIA. It is also possible to observe that the scintillation increases during the equinox months. The number of measurements of S4 $>0.2$ during the months of February, March, October, and November together was 1759 at BOA $(80.1 \%$ of the total of the year), 71 at HUA (52.6\% of the year), and 898 at CUI (93.1\% of the year). The months of February and March happen right before and at the autumnal equinox (March 20), and the months of October and 
November happen right after the spring equinox (September 22) in the southern hemisphere.

Figure 4 shows the S4 index variation during years of maximum solar activity. In this case, the S4 index present values $\leq 0.2$ only from May to August, during the winter time. But now, the S4 index is very intense from September to April at EIA crests and only during equinoxes at the magnetic equator. The number of measurements of S4>0.2 was 68,189 events at BOA (33.6 times higher than solar minimum), 5219 at HUA (58.0 times), and 25,547 at CUI (27.9 times). There is, therefore, an important dependence between amplitude scintillation and solar activity. The moderate to strong scintillations, in this case, are also higher at the EIA crests. The occurrence of scintillations during the equinox months also increased during these years. The number of S4 >0.2 during the months of February, March, October, and November together was 41,331 at BOA $(60.6 \%$ of the total of the year), 4466 at HUA (85.6\% of the year), and 17,355 at CUI $(67.9 \%$ of the year). The dependence on solar activity and on seasonality agrees with previous work, such as [9] from Oceania and [10] from the Asian sector. In the South American sector, [11] found similar results using an hourly analysis from a previous solar cycle. Figure 4 also shows that the occurrence of scintillation was significantly higher at BOA than CUI. Investigations such as [12] show that the asymmetry between northern and southern crests of EIA may be due the longitudinal displacement of the magnetic equator compared with the geographic equator, which is higher than the declination angle, producing a large north-south difference in the effective meridional wind velocity.

\section{Conclusion}

The most important remarks we found in our investigation are the following:

- The occurrence of S4 index with values above 0.2 , which are moderate to strong scintillations, increases substantially when the solar activity increases. In the years analyzed, the number of measurements during the solar maximum increased from around 30 to 60 times compared with solar minimum.

- The occurrence of scintillations is higher at the EIA crests, varying from around 5 to 20 times higher compared with the magnetic equator, with an asymmetry between northern and southern crests possibly due the longitudinal displacement of the magnetic and geographic equators, which produces a difference in the effective meridional wind velocity.

- During the months of February, March, November, and December (near the equinox months), the occurrence of scintillation is much higher, varying from around 5 to 25 times higher compared with other months.
The increase of scintillations during the solar maximum, especially during the equinox months, is due to the enhancement of the ionization during these periods of time. This ionization is located at the background of the equatorial plasma bubbles, which are formed after sunset, when the prereversal enhancement of the eastward electric field takes place and enables the growing of Rayleigh-Taylor instabilities. These instabilities favor the intensification of the irregularities, especially at the EIA crests, and the amplitude scintillations occur more frequently [13-16].

\section{Acknowledgments}

EPM thanks Coordenação de Aperfeiçoamento de Pessoal de Nível Superior Brasil (CAPES) for the financial support providing scholarship through Financial Code 001 as well as MACKPESQUISA; EC thanks the MCTI/CNPq, the National Council for Scientific and Technological Development-CNPq (process nos. 306818/2019-1 and 442101/2018-0) and the São Paulo Research Foundation-FAPESP (process no. 2019/ 05455-2) for individual research support.

\section{References}

1. K. C. Yeh, and C. H. Liu, "Radio Wave Scintillations in the Ionosphere," Proceedings of the IEEE, 70, 4, April 1982, pp. 324-360.

2. M. T. A. H. Muella, M. H. Duarte-Silva, A. O. Moraes, E. R. De Paula, L. F. C. De Rezende, L. Alfonsi, and B. J. Affonso, "Climatology and Modeling of Ionospheric Scintillations and Irregularity Zonal Drifts at the Equatorial Anomaly Crest Region," Annales Geophysicae, 35, November 2017, pp. 1201-1218.

3. M. T. A. H. Muella, E. R. De Paula, and O. F. Jonah, "GPS L1-Frequency Observations of Equatorial Scintillations and Irregularity Zonal Velocities," Survey Geophysics, 35, March 2014, pp. 335-357.

4. P. S. Brahmanandam, G. Uma, J. Y. Liu, Y. H. Chu, N. S. M. P. L. Devi, and Y. Kakinami, "Global S4 Index Variations Observed Using FORMOSAT-3/COSMIC GPS RO Technique During a Solar Minimum Year," Journal of Geophysical Research: Space Physics, 117, A9, September 2012, pp. 1-31.

5. L. Alfonsi, L. Spogli, M. Pezzopane, V. Romano, E. Zuccheretti, G. De Franceschi, M. A. Cabrera, and R. G. Ezquer, "Comparative Analysis of Spread-F Signature and GPS Scintillation Occurrences at Tucumán, Argentina," Journal of Geophysical Research: Space Physics, 118, 7, June 2013, pp. 4483-4502.

6. C. Cesaroni, L. Spogli, L., Alfonsi, G. De Franceschi, L. Ciraolo, J. F. G. Monico, C. Scotto, V. Romano, M. Aquino, and B. Bougard, "L-Band Scintillations and Calibrated Total Electron Content Gradients Over Brazil During the Last Solar Maximum," Journal of Space Weather and Space Climate, 5, A36, December 2015, pp. $1-11$.

7. G. D’Angelo, L. Spogli, C. Cesaroni, V. Sgrigna, L. Alfonsi, and M. Aquino, "GNSS Data Filtering Optimization for Ionospheric Observation," Advances in Space Research, 56, 11, December 2015, pp. 2552-2562.

8. L. Alfonsi, L. Spogli, G. De Franceschi, V. Romano, M. Aquino, A. Dodson, and C. N. Mitchell, "Bipolar 
Climatology of GPS Ionospheric Scintillation at Solar Minimum," Radio Science, 46, 3, June 2011, pp. 1-21.

9. L. D. Nugent, S. Elvidge, and M. J. Angling, "Comparison of Low-Latitude Ionospheric Scintillation Forecasting Techniques Using a Physics-Based Model," Space Weather, 19, 7, June 2021, pp. 1-16.

10. T. C. Nguyen, Use of the East Asia GPS Receiving Network to Observe Ionospheric VTEC Variations, Scintillation and EIA Features During the Solar Cycle 24, Ph.D. dissertation, Technische Universität Berlin, Germany, 2021

11. A. O. Akala, P. H. Doherty, C. E. Valladares, C. S. Carrano, and R. Sheehan, "Statistics of GPS Scintillations Over South America at Three Levels of Solar Activity," Radio Science, 46, RS5018, October 2011, pp. 1-16.

12. N. Balan, P. K. Rajesh, S. Sripathi, S. Tulasiram, J. Y. Liu, and G. J. Bailey, "Modeling and Observations of the North-South Ionospheric Asymmetry at Low Latitudes at Long Deep Solar Minimum," Advances in Space Research, 52, May 2013, pp. 375-382.

13. B. G. Fejer, L. Scherliess, and E. R. De Paula, "Effects of the Vertical Plasma Drifts Velocity on the Generation and
Evolution of Equatorial Spread F," Journal of Geophysical Research, 104, A9, September 1999, pp. 1985919869.

14. L. Spogli, C. Cesaroni, D. D. Mauro, M. Pezzopane, L. Alfonsi, E. Musico, G. Povero, M. Pini, F. Dovis, R. Romero, N. Linty, P. Abadi, F. Nuraeni, A. Husin, M. L. Huy, T. T. Lan, T. V. La, V. G. Pillat, and N. Floury, "Formation of Ionospheric Irregularities Over Southeast Asia During the 2015 St. Patrick's Day Storm," Journal of Geophysical Research: Space Physics, 121, November 2016, pp. 1-23.

15. S. Sripathi, S. Banola, K. Emperumal, B. S. Kumar, and S. M. Radicella, "The Role of Storm Time Electrodynamics in Suppressing the Equatorial Plasma Bubble Development in the Recovery Phase of a Geomagnetic Storm," Journal of Geophysical Research: Space Physics, 123, March 2018, pp. 2336-2350.

16. G. Li, B. Ning, Y. Otsuka, M. A. Abdu, P. Abadi, Z. Liu, L. Spogli, and W. Wan, "Challenges to Equatorial Plasma Bubble and Ionospheric Scintillation Short-Term Forecasting and Future Aspects in East and Southeast Asia," Surveys in Geophysics, 42, September 2020, pp. 201-238. 